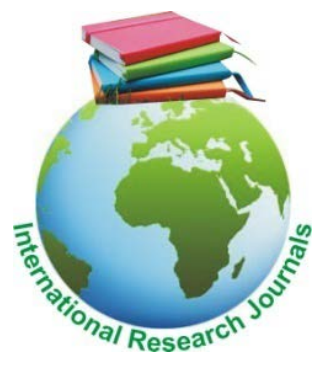

Journal of Research in Environmental Science and Toxicology Vol. 7(1) pp. 10-14 May, 2018

DOI: http:/dx.doi.org/10.14303/jrest.2018.013

Available online http://www.interesjournals.org/JREST

Copyright (c2018 International Research Journals

\title{
Effect of hydrogen sulfide concentration in circulated amine solution on the treated gas in gas treatment plant
}

\author{
Hogr Pirdawood*
}

Laboratory Manager at Gas Treatment Plant (GTP) Laboratory and water Treatment Unit, Iraq, hogromar90@yahoo.com

\begin{abstract}
The concentration of dissolved hydrogen sulfide in circulated amine is necessary to be determined and calculated that useful to make a relationship with hydrogen sulfide in the treated gas after passing through the sweetening process in order to help to control the regeneration process when the research is containing the control system to improve the amine absorption capacity, regeneration efficiency and the concentration of $\mathrm{H}_{2} \mathrm{~S}$ in treated gas for maintaining it under the specification value, Measurement of $\mathrm{H}_{2} \mathrm{~S}$ in treated gas by GC-PFPD Shimadzu-2014 and determination of $\mathrm{H}_{2} \mathrm{~S}$ loading by iodimetric titration in lean amine solution, the relationship between variables were satisfactory, means there is a directly proportional relationship between $\mathrm{H}_{2} \mathrm{~S}$ in both Lean amine and Treated Gas according to increasing and decreasing.

Keywords: $\mathrm{H}_{2} \mathrm{~S}$ loading, Gas Treatment Plant, Treated Gas
\end{abstract}

\section{INTRODUCTION}

Natural sour gas present in a deep beneath the earth's surface. Its composition contains mainly of methane (C1), small amounts of hydrocarbon gases such as (C2-C5), C6+ as liquid condensate and nonhydrocarbon gases such as carbon dioxide, nitrogen, and hydrogen sulfide. Khurmala Gas Treatment Plant (GTP) is located in Southwest ErbilKurdish region $60 \mathrm{~km}$ from Erbil city. It has 60 wells distributed around three wells zones named: North, Middle and South wells stations as shown in Figure 1.

Each group of wells send oil and gas to the Central Process Station (CPS), where CPS complex is responsible

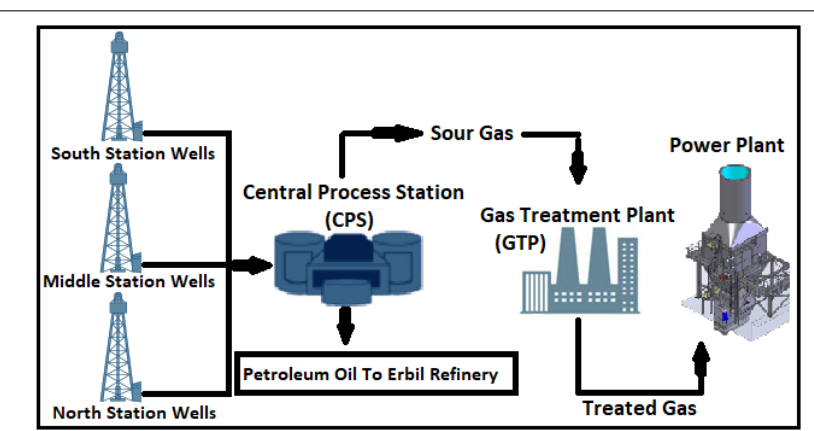

Figure 1. Configuration of Khurmala Dome for separating impurities coming with oil and gas (sludge and no desirable condensates) with production of heavy acid gases (large content of hydrogen sulfide- $\mathrm{H}_{2} \mathrm{~S}$ and carbon dioxide $\mathrm{CO}_{2}$ )

and desalted crude oil for refining. The laboratory analysis has showed that the Khurmala natural sour gas, in normal conditions, has huge quantities of $\mathrm{H}_{2} \mathrm{~S}(3.5 \%)$ and $\mathrm{CO}_{2}$ (5\%) as mentioned in Table 1.

Therefor it cause two major problems representing a significant Threat to an amine gas treating plant are corrosion and instability of operation, resulting in unscheduled upsets an outages (Abdulrahman et al., 2015) (Machenzie et al., 2006).

Table 1. Typical sour gas composition feeding GTP

\begin{tabular}{|c|c|}
\hline Composition & Mole Percentage \\
\hline Methane & $76 \%$ \\
\hline Ethane & $9.50 \%$ \\
\hline Propane & $3.40 \%$ \\
\hline Iso-Butane & $0.30 \%$ \\
\hline n-Butane & $1.20 \%$ \\
\hline Iso-Pentane & $0.50 \%$ \\
\hline n-Pentane & $0.40 \%$ \\
\hline Carbon Dioxide & $5 \%$ \\
\hline Hydrogen Sulfide & $3.50 \%$ \\
\hline Nitrogen & $0.20 \%$ \\
\hline
\end{tabular}


To prevent those problems, the sweetening process must have, to catch at least $99.5 \%$ minimum of $\mathrm{H}_{2} \mathrm{~S}$ through a physical absorption by using aqueous alkanolamine solution such as 50\% of Methyldiethanolamine (MDEA), according to the design unit of Khurmala gas treatment plant this solvent can catch $50 \%$ of $\mathrm{CO}_{2}$ also, the composition of sweet gas can be seen from Table 2 .

Table 2. Typical sweet gas composition feeding GTP.

\begin{tabular}{|c|c|}
\hline Composition & Mole Percentage \\
\hline Methane & $82 \%$ \\
\hline Ethane & $9.50 \%$ \\
\hline Propane & $3.40 \%$ \\
\hline Iso-Butane & $0.30 \%$ \\
\hline n-Butane & $1.20 \%$ \\
\hline Iso-Pentane & $0.50 \%$ \\
\hline n-Pentane & $0.40 \%$ \\
\hline Carbon Dioxide & $3 \%$ \\
\hline Hydrogen Sulfide & $0.02 \%$ \\
\hline Nitrogen & $0.20 \%$ \\
\hline Water vapor content & $0.01 \%$ \\
\hline
\end{tabular}

That's means $\mathrm{H}_{2} \mathrm{~S}$ enter to GTP $3.5 \%$ mole and it is reduced into Sweet/dried gas to maximum 194 ppm. In this order of ideas, natural gas has a significant role in the recent world development especially for Iraq/Kurdish region who is interested to use its natural resources to get energy independence.

The MDEA as used in Gas Treatment Plant utilizes selectivity of the chemical for $\mathrm{H}_{2} \mathrm{~S}$ in Preference to $\mathrm{CO}_{2}$ in no equilibrium situation. The reaction of $\mathrm{H}_{2} \mathrm{~S}$ with MDEA is very fast by proton transfer as is the case with other commonly used amines.

$\mathrm{H}_{2} \mathrm{~S}+\mathrm{R}_{2} \mathrm{NCH}_{3} \leftrightarrow \mathrm{R}_{2} \mathrm{NCH}_{4}^{+}+\mathrm{HS}$

\section{Description of the Research}

Sweetening process taken in Khurmala GTP is shown from the Figure 2, sour gas is passing through the absorber to produce sweetened gas by using special alkanolamine (Methyldiethanolamine-MDEA) to catch acid loading, this amine with high level of acid gas dissolved in it (rich amine) is regenerated to be used again in a close circuit process, as can be seen, top of absorber, regenerator tower, flash drum and condensers are under extremely corrosion process, it is important to mention GTP is mainly carbon steel constructed so, corrosion rate will be expected to be high and must be controlled to avoid lack of production due to shutdowns by this cause. The most commonly used chemical solvent for $\mathrm{H}_{2} \mathrm{~S}$ removal is MDEA. Using of methyldiethanolamine can give us better $\mathrm{H}_{2} \mathrm{~S}$ absorption than carbon $\mathrm{CO}_{2}$ absorption. Typical amine gas sweetening processing block diagram unit represented by Figure 2 .

$\mathrm{CO}_{2}$ firstly reacts with water to form bicarbonate. It is the formation of the bicarbonate which is generally the slow reaction which limits the $\mathrm{CO}_{2}$ reaction to less than equilibrium values at short contact times.

$\mathrm{CO}_{2}+\mathrm{H}_{2} \mathrm{O} \leftrightarrow \mathrm{HCO}_{3}+\mathrm{H}^{+}$

The bicarbonate then undertakes an acid-base reaction with the amine to yield an overall $\mathrm{CO}_{2}$ reaction:

$\mathrm{CO}_{2}+\mathrm{H}_{2} \mathrm{O}+\mathrm{R}_{2} \mathrm{NCH}_{3} \leftrightarrow \mathrm{R}_{2} \mathrm{NCH}_{4}^{+}+\mathrm{HCO}_{3}$

Because of that step (carbon dioxide react with water to form bicarbonate), it may be assumed that the reaction of $\mathrm{H}_{2} \mathrm{~S}$ with MDEA will be in gas phase limited while the $\mathrm{CO}_{2}$ reaction is liquid phase limited (Mark of Schlumberger, 2016) (Douglas et al., 1987) (West, 2008).

The rich solution with absorbed $\mathrm{H}_{2} \mathrm{~S}$ and $\mathrm{CO}_{2}$ exits the absorber at the bottom and flows into a flash tank. The flash tank is operated at a much lower pressure than the absorber, allowing dissolved light hydrocarbons to be released. Before entering the regenerator, the solution is preheated by heat exchange with the lean solution

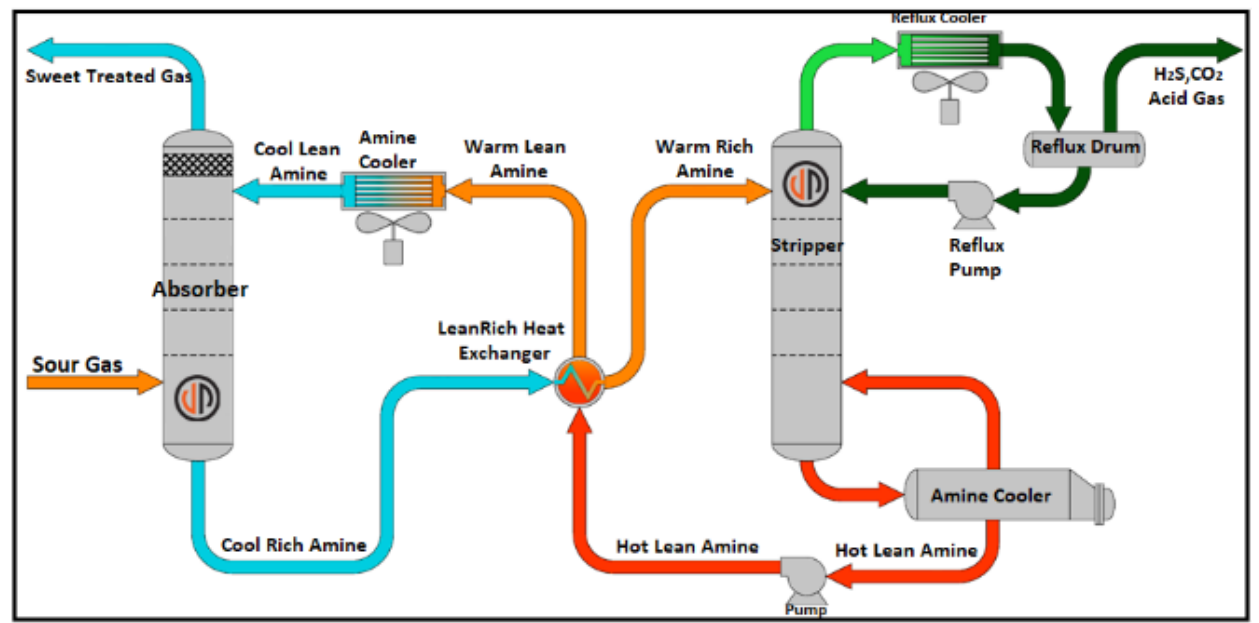

Figure 2. Schematic of simplified gas sweetening plant (GTP) 
coming out of the regenerator. In the regenerator, steam generated in the reboiler is used to strip the acid gases from the rich solution. The regenerated lean amine is then recycled back to the absorber.

\section{SUMMARY OF THE RESEARCH}

One of the objectives of this research is to determine absorbed hydrogen sulfide gas concentrations in an aqueous MDEA stream, the result of this method may be linked to a control system and to founding a desired $\mathrm{H}_{2} \mathrm{~S}$ loading in the lean amine, this is more important to improve regeneration process because of the stripping process is incomplete, and it causes to reduce the efficiency of amine to remove $\mathrm{H}_{2} \mathrm{~S}$ from natural sour gas, so, to maximize this efficiency the amine regeneration process must effectively possible. Then if the data is out of the limit of the desired value then the system either informs the operator who then manually directs a corrective response or else the system automatically orders the corrective response. Another objective of this research is to make a relationship between $\mathrm{H}_{2} \mathrm{~S}$ in lean amine with Treated Gas when all the samples have taken at the same condition $3.5 \% \mathrm{H}_{2} \mathrm{~S}$ and $5 \%$ of $\mathrm{CO}_{2}$ and same flow of the feed. The control system then compares the $\mathrm{H}_{2} \mathrm{~S}$ loading in lean amine and treated gas to have an $\mathrm{H}_{2} \mathrm{~S}$ in treated gas under the range of the specification (Universal Oil Processing, 1981).

\section{RESULTS AND DISCUSSION}

A high precise method is used for the determination of dissolved hydrogen sulfide concentration in lean amine by oxidation with the standard iodine solution $0.05 \mathrm{M}$ in acidic medium apparent hydrogen. If thiosulfate is present, is also titrated an included $\mathrm{H}_{2} \mathrm{~S}$ in the calculation.

\section{SUMMARY}

For a solution containing more than 100 grain of $\mathrm{H}_{2} \mathrm{~S}$ per gallon or where better precision is required. A portion of amine sample is pipette into an acidic water solution containing an excess standard iodine solution. The excess of iodine is back titrated with standard sodium thiosulfate solution using starch as indicator.

Precision method: Pipette $1 \mathrm{~mL}$ sample into a $250 \mathrm{~mL}$ Erlenmeyer flask containing a magnetic stirring bar and $100 \mathrm{~mL}$ of water with the viscous sample, rinse the pipette with water and add the rinsing into the flask and then Pipette a $1 \mathrm{~mL}$ of $\mathrm{HCl}$, and add approximately $2 \mathrm{~mL}$ of starch indicator solution. The solution titrated with standard iodine solution until reach a blue color which means the endpoint.

The procedure followed involved 23 samples of lean amine and 23 samples of treated gas which all of them were taken at the same operation condition $94 \mathrm{MMSCF} / \mathrm{D}$ of feed which contains $3.5 \% \mathrm{H}_{2} \mathrm{~S}$ and $5 \% \mathrm{CO}_{2}$.

Shimadzu Gas Chromatography coupled with Pulsed Flame Photometric Detection (GC-PFPD) as shown from the Figure 3.

\section{PFPD}

It is almost new detection that can be used in analytical chemistry, it invented about 30 years ago.it uses a flame like its namesake, PFPD came from the improvement of old FPD, FPD was generally used for detection $S$ and $F$ only, but PFPD has the capability and enhanced to detect $\mathrm{N}, \mathrm{As}, \mathrm{Sn}, \mathrm{Se}, \mathrm{Ge}, \mathrm{Te}, \mathrm{Sb}, \mathrm{Br}$, Ga and selective detection of sulphur and phosphorus.

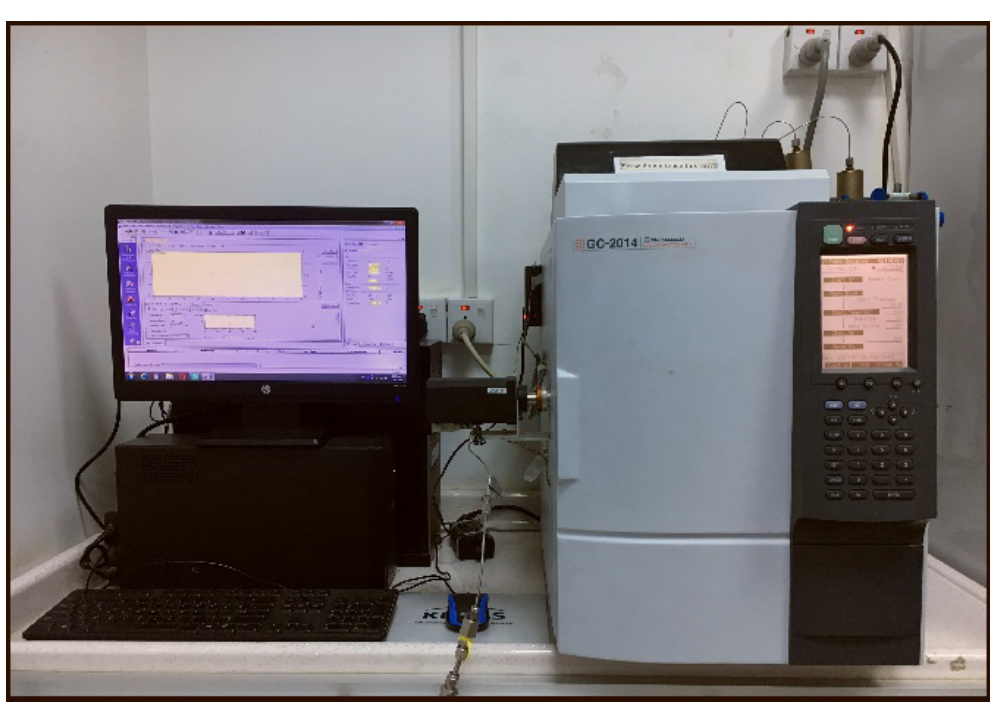

Figure 3. Shimadzu Gas chromatography, Model-2014 GC-PFPD and helium as carrier gas used to detect $\mathrm{H}_{2} \mathrm{~S}$ in Treated in ppm level. 
The basic of PFPD working depends on the flame source and combustible gas flow, hydrogen and air used as a mixture of combustible gases with the sample components which are in a continuous flow into the flame chamber, the combustible gas is also fed separately. Firstly the ignited flame is propagated back to the flame chamber and terminated in few milliseconds because of the pulsed flame can't be continuous in the combustor holder small hole. Then the continuous gas flow makes additional ignition in few hundred milliseconds, the emitted light transferred to the photomultiplier tube through the glass filter and detected (American Standard for Testing and materials, 2010) (Stevens et al., 1969) (Kientz and Verweij, 1987) (Godoi et al., 2003). PFPD diagram can be seen from the Figure 4.

Due to the fact that $\mathrm{H}_{2} \mathrm{~S}$ is highly corrosive gas in nature. The products of dissociation of $\mathrm{H}_{2} \mathrm{~S}$ gas is aggressive and can catalyze the electrochemical reactions, especially the dissolution of Fe to form iron sulfide FeS, therefore the study of $\mathrm{H}_{2} \mathrm{~S}$ concentration in both lean amine and

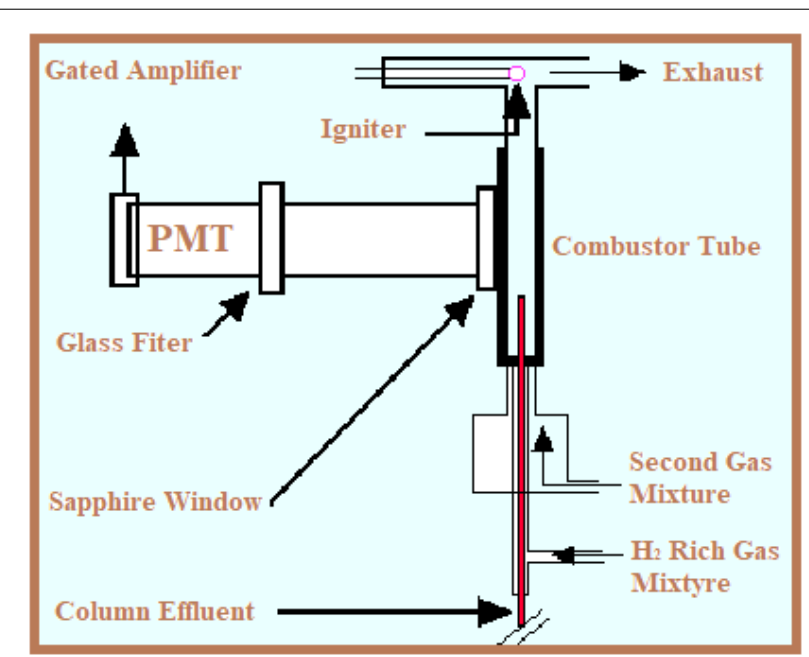

Figure 4: PFPD diagram

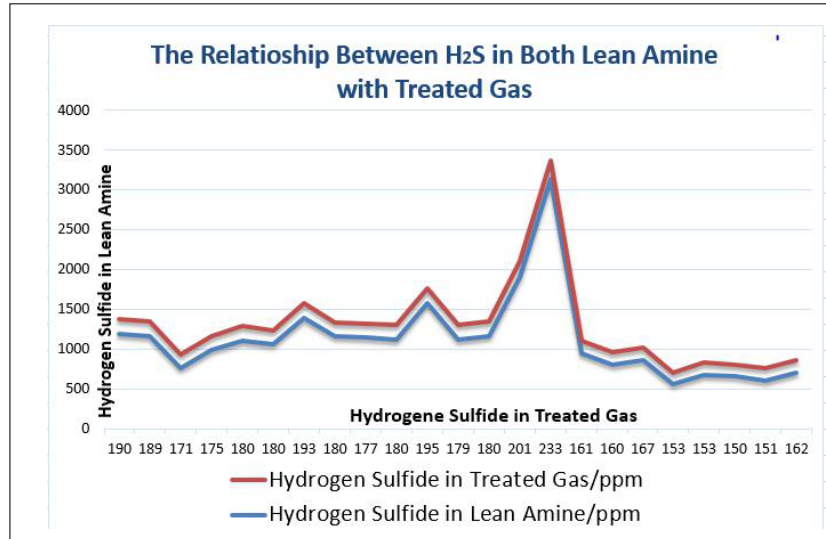

Figure 5. The relation between $\mathrm{H}_{2} \mathrm{~S}$ in Lean amine and treated gas treated gas is more important to have a monitored and highly effective regeneration system and preventing the problems causing by $\mathrm{H}_{2} \mathrm{~S}$ in treated gas. The relation between $\mathrm{H}_{2} \mathrm{~S}$ in both lean amine and treated gas represented by Figure 5 .

Figure 3 explained the relation between $\mathrm{H}_{2} \mathrm{~S}$ concentration in both lean amine and treated gas. It is obvious that with the increase of $\mathrm{H}_{2} \mathrm{~S}$ loading in lean amine solution the value of $\mathrm{H}_{2} \mathrm{~S}$ concentration in treated gas is also increased due to the decreasing of lean amine catching capacity by more protonated amine ions $\left(\mathrm{R}_{2} \mathrm{NH}_{2}{ }^{+}\right)$.

$\mathrm{H}_{2} \mathrm{~S}+\mathrm{CH}_{3} \mathrm{H}\left(\mathrm{C}_{2} \mathrm{H}_{4} \mathrm{OH}\right)_{2} \rightarrow \mathrm{HS}^{-}+\mathrm{CH}_{3} \mathrm{~N}_{(}\left(\mathrm{C}_{2} \mathrm{H}_{4} \mathrm{OH}\right)_{2} \mathrm{H}^{+}$

The greater the concentration of protonated amine ions

$\left(\mathrm{CH}_{3} \mathrm{~N}\left(\mathrm{C}_{2} \mathrm{H}_{4} \mathrm{OH}\right)_{2} \mathrm{H}^{+}\right)$,

The greater will be the concentration of $\mathrm{H}_{2} \mathrm{~S}$ in treated gas, there is a direct proportional relationship between them (Nielsen et al., 1995) (Snowdon, 2001) (American Standard for Testing and Materials, 2003).

\section{ACKNOWLEDGEMENT}

The author would like to thank the Danish Development Agency (DANIDA) for financial support via Haramaya Camel Dairy Project.

\section{REFERENCES}

Abdulrahman R, Kamal I and Ali J (2015). Natural Gas Desulfurization process by MDEA amine: The preferable engineering design procedure. International Journal of Engineering Trendsand Technology. 28(5): 241-248.

American Standard for Testing and Materials (2003). Standard test method for analysis of natural gas by gas chromatography. USA. D1945.

American Standard for Testing and materials (2010). Standard Test Method for Determination of Sulfur Compounds in Natural Gas and Gaseous Fuels by Gas Chromatography and Flame Photometric Detection. USA. D6228

Douglas HM, Francis CP, Christina AD and Bullin JA (1987). Design \& operation of selective sweetening plant Using MDEA. Energy Progress. 31-36.

Godoi AFL, Favoreto R and Santiago-Silva M (2003). $\mathrm{GC}$ analysis of organotin compounds using pulsed flame photometric detection and conventional flame photometric detection. Chromatographia. 58(1-2): 97101.

KientzCE and Verweij A(1987). The application of a flame photometric detector in packed microcapillary liquid chromatography: Detection of organophosphates. Int. J. Environ. Anal. Chem. 30(4): 255-263. 
Machenzie D, Daniel C and Bullin J (2006). Design \& operation of selective sweetening plant Using MDEA, USA.

Mark of Schlumberger (2016). Amine gas sweetening system: Field-proven gas sweetening for complex operations.

Nielsen RB, Lewis KR, McCullough JG and Hansen DA (1995). Controlling corrosion in amine treating plants. In Proceedings of the Laurance Reid Gas Conditioning Conference, Norman, Oklahoma.

Snowdon LR (2001). Natural gas composition in a geological environment and the implications for the processes of generation and preservation. Org. Geochem. 32(7): 913-931.

Stevens RK, O'Keeffe AE and Ortman GC (1969). Absolute calibration of a flame photometric detector to volatile sulfur compounds at sub-part-per-million levels. Environ. Sci. Technol. 3(7): 652-655.

Universal Oil Processing (1981). Apparent hydrogen Sulfide in amine solution. Method 827.

West C (2008). Efficient Use of Fuel Gas in Amine Plants. Module 14 of 17. 